of the third-book method, I can readily show that such an inference was by no means so absurd as might be inferred from his remarks about the oldness of the problem. For I remember distinctly an occasion on which the solution of this problem was required during a lecture at King's College, London, at which my friends Baily (second wrangler in 1860) and Hudson (third wrangler in 1861) were present. Three of the students at once submitted to the lecturer the solution by the sixth-book method (which no one can well miss) and the lecturer (a second wrangler), while admitting that the solution was not very pleasing, was unable at the moment to suggest a better; he added, jokingly, that the best way to solve the problem would be to describe a parabola having the given point as focus and either of the given lines as directrix. Now, he had not been long engaged in teaching, and it may be perfertly true that one who had been so engaged "would certainly have in his memory one or more solutions of this problem ;" but this would depend on the subjects he had been engaged upon. If he chanced to be one of the most eminent mathematical professors at Cambridge, it is probable that no problem in the higher analysis would be unknown to him, but the odds would be rather against than in favour of his being familiar with the best solutions of geometrical problems, just as the odds would be against his being proficient in the rules for "Barter," "Tare and Trett," and "Alligation Partial."

From letters which have reached me I find that the general purport of my letter has been misapprehended, since some appear to infer that $\mathrm{I}$ question the geometrical power of our University mathematicians. I meant nothing so unreasonable. We have geometricians who rival (and I believe more than rival) in power the best Continental geometricians. But their geometrical strength has not been attained during their University career; and no one who considers carefully the mathernatical course at either University, can believe that it tends either to form geometricians or to foster geometrical taste.

I candidly admit that 1 do not speak of either course from personal experience. All I know of geometry was learned before my Cambridge time, and very nearly all I know of analytical mithematics was learned after that time. But I know quite well the nature of each course, and can sustain my statement that our universities do not encourage the study of geometry. Whether they should do so is a matter on which I have expressed no opinion.

RICHD, A. PROCTOR

Brighton, Oct. ?

P.S.-Mr. Todhunter refers to the actual solution of the problem as a "matter of some interest, though of course unconnected with the theoretical solution." As I have had some experience in constructive geometry (having always made it a practice to solve astronomical problems constructively betore proceeding: to numerical calculation), I may be permitted to make some remarks on this point. First $I$ would add to the compasses and parallel ruler (the only instruments mentioned by $\mathrm{Mr}$. Todhunter) that most useful instrument the square. With this instrumen (which would be needed in any case) the following construction would be as convenient as the one founded on the sixth-book solution. The problem, be it remembered, requires that a circle should be described through a given point to touch two given straight lines. Let $\mathrm{P}$ be the point, $\mathrm{AB}$ and $\mathrm{AFCG}$ the lines, A HDK the bisector of BAC (this bisector must be drawn in both methods, so that I leave its construction untouched); with the square draw CPD square to $\mathrm{AK}$, and $\mathrm{PE}$ square to $\mathrm{CD}$; with centre $\mathrm{D}$ draw circular arc $\mathrm{PE}$; with centre $\mathrm{C}$ and distance $\mathrm{PE}$ centre $D$ draw circular arc $\mathrm{PE}$; with centre $\mathrm{C}$ arcle $\mathrm{FLG}$; then $\mathrm{FH}$ and $\mathrm{GK}$ drawn square to. $\mathrm{AG}$ (with the square) are radii of the two circles fulfilling the conditions

\section{Prof. Newcomb and Mr. Stone}

IN Mr. Proctor's letter to NATURE of the 23rd ult, he remarks that Prof. Newcomb had stated to him that he was bewildered at having a discussion of the transits of Venus and the parallax of the Sun, deducible from them, pior to that of Mr. Stone, attributed to himself; and Mr. Proctor goes on to state that he was justified in his belief that such a discussion had been made because a writer, signing himself "P. S." had had been made because a letter appearing in the Astronomical Register for December 1868 . He further gives two reasons for the "P.S." The first of them is that there is strong internal evidence that the writer was a distinguished astronomer having those as his initials for a part of his initials, it would be more correct to say); of this it seems scarcely needful to say more, as the writer in question may prefer not to be unearthed. But of Mr. Proctor's other reason, may I be permitted to say a word? It is that the assertion of "P.S." was "permitted to remain uncorrected."

Had Mr. Proctor turned to the very next number of the Astronomical Register (that for. January 1869 ) he would have found a letter signed also with initials "W.T. L." in which "P. S.'s" assertion that Prof. Newcomb had published any dis. cussion of the transit of Venus in I 769 , is most emphatically contradicted. "P.S.," it is true, made a rejoinder in the March number of the Register (page 65) but in it he neither denies "W. T. L.'s" contradiction, nor refers (as of course he could not) to any original investigation of the transit-of-Venus problem by Prof. Newcomb. He contented himself with the rather uninfelligible remark that "W.T. L.'s" answer was not in "the spirit of the age we live in." The latter writer in the following number of the Kegister (page 88) pointed how, in all probability, the mistake of "P.S." had arisen from misunderstanding part of the title of a paper by Prof. Newcomb on the Distance of the Sun, and the matter dropped.

Now, as Prof. Newcomb was as likely to have seen "W. T. L.'s". contradiction as "P. S.'s" assertion, there would certainly seem no necessity for his further disowning himself what "P. S." had claimed for him.

Blackheath, Oct. 2

\section{Note on the Cycloid}

I Do not know whether it has been noticed that the cycloid is a projection of the common helix (thread-inclined $45^{\circ}$ ). I suppose the property must have long since been recognised, but have not seen it mentioned.

The proof is very simple, and may be thus presented :-

Suppose a vertical circle to have its plane east and west (a luminous point, for the nonce), the sun in the meridian and $45^{\circ}$ high. Then the shadow of the circle on a horizontal plane will clearly be a circle; and further, if a point move uniformly round the vertical circle, the shadow of the point will move uniformly round the shadow-circle. Now, let the centre of the vertical circle advance horizontally towards the south, while a point moves round its circumference at the same uniform rate. The moving point will describe a right helix with a thread-inclination of $45^{\circ}$. Its shadow will move uniformly round the shadow-circle while the centre of this circle advances uniform'y and at the same rate in a straight line. It will therefore describe a cycloid.

It is obvious that all the varieties of curtate and prolate-cycloids may be obtained as projections of helices, by changing the threadinclination.

Also it is obvious that if the sun (or the point of projection) were in the zenith, the shadow (or projection) of the helix first dealt with would be the curve called "the companion to the cycloid." RICHARD A. PROCTOR

\section{Is Blue a Primary Colour?}

IN recent works on colour blue is called a primary colour. If blue is a primary colour a mixture of yellow and blue transparent pigments could not produce green, but would form an opaque combination. The colour produced by a mixture of yellow and blue pigments-if blue is an elementary colourwill depend on the colour reflected by the coloured layer itself, and not on the light passed through it from the white surface underneath. The briliancy of the green produced by mixing yellow and blue pigment, is a measure of the transparency, to the green rays, of the blue pigment employed. Or in other words, there is as much green in the blue pigment employed, as there is green in the green produced by mixing that pigment with yellow. Blue must, therefore, be a compound colour, since the tilué pigment passes the green rays.

Further. When the light reflected from blue substances is examined with a prism, it is found to be composed of green and violet. Again, when green and violet are combined by means of a rotating disc, blue is produced. By varying the proportions of green and violet any colour from green through blue-green or sea-green, blue, blue violet or indigo to violet, may be obtained. Again, when the solar spectrum is thrown on a blue surface, the green and the violet rays are reflected in the same way as a yellow surface reflects the red and the green rays.

The following is a simple way of showing that blue is not an elementary colour, and that violet is an elementary colour :Take a piece of red, a piece of green, and a piece of violet 